\title{
BMJ Open Acuity level of care as a predictor of case fatality and prolonged hospital stay in patients with COVID-19: a hospital- based observational follow-up study from Pakistan
}

\author{
Aysha Almas (1) , ${ }^{1}$ Zain Mushtaq, ${ }^{1}$ Jette Moller $^{2}$
}

To cite: Almas A, Mushtaq Z, Moller J. Acuity level of care as a predictor of case fatality and prolonged hospital stay in patients with COVID-19: a hospital-based observational follow-up study from Pakistan. BMJ Open 2021;11:e045414. doi:10.1136/ bmjopen-2020-045414

- Prepublication history for this paper is available online. To view these files, please visit the journal online (http://dx.doi org/10.1136/bmjopen-2020045414).

Received 30 September 2020 Accepted 17 May 2021

Check for updates

(c) Author(s) (or their employer(s)) 2021. Re-use permitted under CC BY-NC. No commercial re-use. See rights and permissions. Published by BMJ.

${ }^{1}$ Medicine, Aga Khan University, Karachi, Pakistan

${ }^{2}$ Global Public Health, Karolinska Institutet, Stockholm, Sweden

Correspondence to

Dr Aysha Almas;

aysha.almas@aku.edu

\section{ABSTRACT}

Objectives To determine if there is an association between acuity level of care (ALC), case fatality and length of stay in patients admitted to hospital due to COVID-19. Design A hospital-based observational follow-up study. Setting Internal Medicine Service of the Aga Khan University Hospital, Pakistan, from 26 February 2020 to 30 June 2020.

Participants Adult patients with confirmed COVID-19, aged $\geq 18$ years.

Methods ALC was categorised into low, intermediate and high level and patients were triaged using the standard emergency severity illness score. All patients were followed until the end of hospital admission for the outcome of case fatality and length of stay.

Results A total of 822 patients with COVID-19 were admitted during the study period and 699 met inclusion criteria. The mean age was 54.5 years and $67 \%$ were males; $50.4 \%$ were triaged to low, $42.5 \%$ to intermediate and $7.2 \%$ to high acuity care. The overall case-fatality rate was $11.6 \%$, with the highest (52\%) in high acuity level followed by $16.2 \%$ in intermediate and $2 \%$ in low acuity care. Acuity level was associated with case fatality, with an $\mathrm{HR}(95 \% \mathrm{Cl})$ of 5.0 (2.0 to 12.1) for high versus low acuity care and an HR of $2.7(1.2,6.4)$ for intermediate versus low acuity care, after adjusting for age, sex and common comorbidities including diabetes, hypertension, ischaemic heart disease and chronic lung disease. Similarly, acuity level was also associated with length of hospital stay. Conclusion High and intermediate acuity level is associated with higher case fatality rate and prolonged length of hospital stay in patients admitted with COVID-19. In resource-limited settings where the provision of high acuity care is limited, the intermediate care acuity could serve as a useful strategy to treat relatively less critical patients with COVID-19.

\section{INTRODUCTION}

COVID-19 is caused by SARS-CoV-2, the novel coronavirus, which rapidly converted into a pandemic causing global concern. ${ }^{1-3}$ More than 26 million cases were reported until 9 September 2020, of which 871166 died. ${ }^{4}$
Strengths and limitations of this study

- This study determines the link between acuity level of care and case fatality and length of stay in patients with COVID-19 in a lower-middle-income country.

- This observational follow-up study and data extracted from medical records reduce possible recall bias and selection bias.

- It is a single-centre hospital-based study and cannot be generalised to the fatality rates in the general population.

- Clinical and laboratory details of patients are not reported in detail in this study.

Preparing to combat this pandemic is more challenging for low-income and middleincome countries (LMICs) such as Pakistan with a population of over 212 million and a total health expenditure of only $2.6 \%$ of the gross domestic product. The first case of COVID-19 was reported in Karachi on 26 February 2020, and although populationbased screening for COVID-19 was not done, 298509 cases had been reported with an overall mortality of $2.5 \% .^{5}$ Availability of critical care units and trained healthcare staff for managing patients with COVID-19 due to limited resources is a major challenge for hospitals in Pakistan. Due to this limitation, some critical patients are admitted to intermediate care units instead, who do not require urgent invasive ventilation. However, the outcome of these COVID-19 patients in terms of fatality or progression of the infection has not been reported thus far.

Acuity level of care (ALC) to patients is defined as an attribute of severity, intensity paired with patient, provider or system, according to Holzemer's Outcomes Model for Health Care Research. ${ }^{6}$ Besides, it also 
encompasses physical, psychological and nursing care needs, workload and complexity, urgency and triage scales. ALC level in healthcare is linked with patients' safety and mortality. ${ }^{78}$ An adequate number of beds with the right level of acuity to manage potentially critical patients with COVID-19 is therefore crucial to decrease suffering and avoid high mortality. However, whether the level of acuity, more specifically of intermediate care units, is linked to a favourable or less favourable outcome in patients with COVID-19 is not well known and especially not in LMIC. The WHO reports that $80 \%$ of those infected by SARS-CoV-2 develop mild symptoms, $14 \%$ have severe symptoms and $6 \%$ will complicate into a critical disease. ${ }^{9}$ In a crisis situation such as the COVID-19 pandemic, institutional-based algorithms can aid clinicians to triage patients more efficiently. ${ }^{10}$ Due to the acute shortage of ventilators that many LMICs are facing, the decision to admit patients to high acuity becomes difficult. ${ }^{11}$ Also, in such LMICs triaging and admitting to the correct level of care is not only important for patient outcomes but also helps in prioritising healthcare resources efficiently. In general, patients triaged as having a higher ALC require a greater number of emergency or admitting service resources. ${ }^{12}$ Hence, ALC is an indirect measure of the severity of illness of patients and required healthcare resources to manage them. Illness severity scores are linked to the acuity of hospital settings. ${ }^{13}$ Five-level systems such as the Emergency Severity Index (ESI) and the Canadian Triage Acuity System are considered more reliable than three-level systems and are commonly used to triage based on the severity of illness and acuity. ${ }^{1415}$

The Centers for Disease Control(CDC) and Prevention, USA, categorises patients with COVID-19 requiring hospitalisation into three levels of patient acuity. ${ }^{16}$ Non-acute care means general, low-level care for mild-to-moderately symptomatic patients who may require oxygen (less than or equal to $2 \mathrm{~L} / \mathrm{min}$ ) but does not require extensive nursing care; mid-level care for moderately symptomatic patients means patients who require high oxygen support (more than $2 \mathrm{~L} / \mathrm{min}$ ), nursing care and assistance with activities of daily living and high acuity care for patients means patients who require significant ventilatory support, including intensive monitoring. Case fatality or length of hospital stay concerning the three ALC has not been reported in detail. The case fatality reported for patients with COVID-19 shows large variability. Studies have reported mortality ranging from $2 \%$ to $50 \%{ }^{3}{ }^{37}$ The discrepancies in mortality might arise from differences in age groups affected, the testing capacity and whether there were massive screenings. ${ }^{18}$ Also, in a systematic review of 52 studies, the majority from China, median length of hospital stay ranged from 4 to 53 days within China and 4 to 21 days outside of China. ${ }^{19}$

In Pakistan, a significant number of critically ill patients are admitted to intermediate or special care units (SCU) due to a shortage of intensive care unit beds. ${ }^{20}$ However, there is no empirical evidence of favourable or unfavourable outcomes of patients with COVID-19 admitted to various ALC, specifically intermediate care units, from LMIC. Recognising the correct ALC required for patients with COVID-19 and determining their outcome is important, first because patients in COVID-19 units are alone without family members. Second, in settings with limited resources patients who need high acuity care could be cared for in intermediate care units with more vigilance and gain favourable outcome compared with not finding high acuity care at all. Third, the cost is an additional important factor. In LMIC such as Pakistan, patients are paying out of their pocket and high acuity care is more expensive than lower levels of ALC. We hypothesise that recognising the correct level of acuity at the time of admission for COVID-19-positive patients in LMIC such as Pakistan is linked to their outcome as this might be a more cost-effective approach to delivering care with limited resources. We, therefore, aim to determine if ALC is a predictor of case fatality and length of hospital stay in patients admitted with COVID-19.

\section{METHODS}

We conducted an observational follow-up study at the Aga Khan University Hospital (AKUH) from 26 February 2020 (index case in Pakistan) to 30 June 2020. All cases of COVID-19 admitted according to ALC (low, intermediate or high) during this period were followed up for case fatality and length of hospital stay. A total of 822 adult patients included (aged older than $>18$ years) with positive reverse transcription polymerase chain reaction for COVID-19 were admitted from the emergency room or through clinics to the COVID-19 diagnostic and testing zone of the hospital. Patients admitted to services other than internal medicine (eg, surgical or obstetrics due to urgent surgical needs for preoperative screening for COVID-19) were excluded ( $\mathrm{n}=123)$ and 699 patients were categorised into low, intermediate or high acuity care level.

ALC was categorised as low, intermediate or high level according to CDC, USA, for management of COVID-19. ${ }^{16}$ Low acuity level care or general ward care is defined as a dedicated ward for patients with COVID-19 who require hospital care or oxygen administration but do not have severe disease. Oxygen administration via nasal cannula/mask of maximum 4 $\mathrm{L} /$ min with intermittent monitoring of oxygen saturation and breathing frequency 3-4 times per day, intermediate care or SCU are defined as units dedicated for patients who require oxygen therapy and continuous monitoring of vital parameters (at least $\mathrm{SpO}_{2}$, ideally blood pressure, heart rate and respiratory rate). Oxygen administration is done via nasal cannula/ probe, venturi mask or reservoir mask. In ideal circumstances, the use of high-flow oxygen therapy and noninvasive ventilation (NIV) is not recommended in general or outside of an intensive care unit due to the 
Table 1 Characteristics of the three levels of acuity at the Aga Khan University Hospital

\begin{tabular}{llll}
\hline Characteristics of care & Low-level acuity & Intermediate-level acuity & High-level acuity \\
\hline Emergency severity illness score & Stable patients ${ }^{*}(\mathrm{P} 3)$ & $\begin{array}{l}\text { Unstable and critical patient† } \\
\text { (P2) }\end{array}$ & $\begin{array}{l}\text { Critical and life-threatening } \\
\text { patient (P1) }\end{array}$ \\
Vitals monitoring & Every 6 hours & Continuous monitoring & Continuous monitoring \\
Nurse-to-patient ratio & $1: 5$ & $1: 3-4$ & $1: 1$ \\
Doctor-to-patient ratio & $1: 8$ & $1: 4$ & $1: 3$ \\
Non-invasive ventilation available & No & Yes & Yes \\
Invasive ventilation available & No & No & Yes \\
\hline Cost in US\$day & 154 & 193 & 290 \\
\hline
\end{tabular}

${ }^{*}$ Requiring hospital admission or oxygen.

†If unstable patients remain critical in the emergency room, they were initially admitted to high acuity.

risk of aerosols and of rapid deterioration in the case of system failure. ${ }^{21}$ However, in the intermediate care unit in the AKUH, NIV is used in intermediate care beds as there is a limited capacity of Intensive care unit (ICU) beds. Intensive or high acuity care is dedicated to patients who have increasing organ dysfunction (eg, increasing respiratory failure) or require invasive ventilation or 1:1 nursing. Table 1 demonstrates the specification of the three ALC.

The decision of placing the patients into the different ALC was based on the standard ESI. ${ }^{15}$ According to the triage process, patients with systolic blood pressure $<100 \mathrm{~mm} \mathrm{Hg}$, or diastolic blood pressure $<60 \mathrm{~mm}$ $\mathrm{Hg}$, or heart rate $>100$ beats per minute, or oxygen saturation $<92 \%$, or who had altered mental status, or had respiratory rate $>24$ breaths per minute were considered as unstable and were admitted to intermediate acuity level. If unstable patients required invasive ventilation or invasive haemodynamic monitoring, they were admitted to high acuity care. However, when high acuity care beds were not available, those patients who were impending invasive ventilation (on more than $8 \mathrm{~L}$ oxygen and required continuous NIV) or required limited haemodynamic monitoring (only central venous pressure monitoring) were admitted to intermediate care units instead. The outcome of case fatality and length of stay were extracted through the hospital information management system and the COVID-19 diagnostic and testing zone daily log.

Age, sex and comorbidity of hypertension, diabetes, ischaemic heart disease and chronic lung disease (asthma and chronic obstructive lung disease) were recorded and considered as confounders. Data on patients who required invasive ventilation during inpatient stay (which required shifting to high-level acuity) were recorded. The data were extracted from the daily automated admission log of the COVID-19 diagnostic and testing zone which was maintained by head nurses of the respective units. Additionally, for validation of the data, the COVID-19-related code 07982 was extracted from the hospital information and management system based on the International
Classification of Disease-9 coding (ICD-9), as well as data on comorbid conditions: hypertension (ICD-9: 4019), diabetes (25000-25093), ischaemic heart disease (41001-41091), asthma (49390-49392) and chronic obstructive lung disease (49121), ventilation (96.71 and 96.72).

\section{Analysis}

For the descriptive statistics, the mean (SD) or median (IQR) as appropriate was used for continuous variables and frequency and percentages for categorical variables. The $\chi^{2}$ test, analysis of variance and Kruskal-Wallis test were used as appropriate to compare the three levels of acuity and a $p$ value of $<0.05$ was considered statistically significant. The ALC on admission was considered for ascertaining the level of acuity. If there was a change in acuity level, only the acuity level on admission was considered. The case fatality ratio (CFR), that is, the proportion of individuals diagnosed with COVID-19 concerning those who died of COVID-19 was used as a measure of severity among detected cases $(\mathrm{CFR}=$ Number of deaths from COVID-19/number of confirmed cases of COVID-19 disease $\times 100){ }^{22}$ Time-to-event (death) analysis was performed using Cox regression. Endpoints considered were time of fatality, end of inpatient stay or end of the study period. Time to event was calculated in days, that is, number of days from admission date to date of in-hospital death, discharge or end of the study period. Models were constructed for the association of acuity level, adjusting for age and sex in model 1, and further adjustment for comorbid conditions in model 2. Linear regression was used to determine the association between acuity with a length of stay using a similar modelling strategy HR and beta coefficients with corresponding 95\% CIs were reported. Statistical package for social sciences V.22 was used for all analyses.

\section{RESULTS}

Characteristics of the patients with COVID-19 are shown in table 2. The mean age was 54.5 years and $67 \%$ were males. A quarter of the patients were in the age range 
Table 2 Characteristics of patients with COVID-19, overall and according to the level of acuity (N=699)

\begin{tabular}{|c|c|c|c|c|c|}
\hline & \multirow[b]{3}{*}{ Overall } & \multicolumn{3}{|l|}{ Acuity care level } & \multirow{3}{*}{$P$ value } \\
\hline & & Low & Intermediate & High & \\
\hline & & $n=352(50.4 \%)$ & $\mathrm{n}=297(42.5 \%)$ & $\mathrm{n}=50(7.2 \%)$ & \\
\hline Mean (SD) age & $54.5(15.4)$ & $50.7(16)$ & $59(14)$ & $56(11)$ & $<0.001$ \\
\hline \multicolumn{6}{|l|}{ Age group (in years) } \\
\hline $41-50$ & $128(18.3)$ & $76(21.6)$ & $42(14.1)$ & $10(20)$ & \\
\hline $51-60$ & $178(25.5)$ & $78(22.2)$ & $84(28.3)$ & $16(32)$ & \\
\hline $61-70$ & $151(21.6)$ & $61(17.3)$ & $77(25)$ & $13(26)$ & \\
\hline$>70$ & $106(15.2)$ & $40(11.4)$ & $61(20.5)$ & $5(10)$ & $<0.001$ \\
\hline \multicolumn{6}{|l|}{ Comorbidity } \\
\hline Diabetes & $236(33.8)$ & $92(26.1)$ & $126(42.4)$ & $18(36)$ & $<0.001$ \\
\hline Hypertension & $219(31.3)$ & $100(28.4)$ & $104(35.0)$ & $15(30)$ & 0.1 \\
\hline Ischaemic heart disease & $84(12)$ & $24(6.8)$ & $47(15.8)$ & $13(26)$ & $<0.001$ \\
\hline Chronic lung disease & $39(5.6)$ & $19(5.4)$ & $18(6.1)$ & $2(1)$ & 0.8 \\
\hline Required non-Invasive ventilation & $159(22.7)$ & $18(5.1)^{\star}$ & $128(43.1)$ & 13(26) & $<0.001$ \\
\hline Required invasive ventilation & $64(9.2)$ & $7(2) \dagger$ & $28(9.4) \dagger$ & $29(58)$ & $<0.001$ \\
\hline Case fatality ratio & $81(11.6)$ & $7(2)$ & $48(16.2)$ & $26(52)$ & $<0.001$ \\
\hline Mean length of stay (SD) & $7.26(6.3)$ & $5.3(5.3)$ & $8.3(5.7)$ & $14.2(9.1)$ & $<0.001$ \\
\hline
\end{tabular}

*Shifted to higher care later or applied with palliative intent.

†Patients were moved to a high acuity level during their stay if they required invasive ventilation; the acuity level on admission was used in the analysis.

51-60 years. Mean (SD) of the age of patients admitted to intermediate care units was higher (59 (14) years) than those admitted in low acuity care (50.7 (16) years) or high acuity care (56 (11) years). Forty-five per cent of the patients aged $>60$ years were admitted in intermediate acuity care, followed by $36 \%$ in high acuity and $28 \%$ in low acuity care. Diabetes was the most common comorbid condition $(34 \%)$ and $9.0 \%$ of patients required invasive ventilation. Among comorbid conditions, more patients with diabetes $(42.4 \%)$ were admitted to intermediate care and more patients with ischaemic heart disease were admitted in high acuity care.

\section{Acuity level of care}

Most of the patients were admitted to low acuity care $(50.4 \%)$, followed by intermediate $(42.5 \%)$ and $7.2 \%$ to high acuity care. The patients requiring a higher level of acuity (intermediate and high) were older than those in low acuity care (table 2 ).

Figure 1 demonstrates the trend of patients admitted with confirmed COVID-19 from 26 February to 30 June. There was a rise in admissions to low-level and intermediate-level acuity (28 to 179 in low acuity care and
7 to 136 in intermediate acuity care, respectively), while the number of admissions in high-level acuity remained similar throughout the period. Also, at least $17 \%$ of

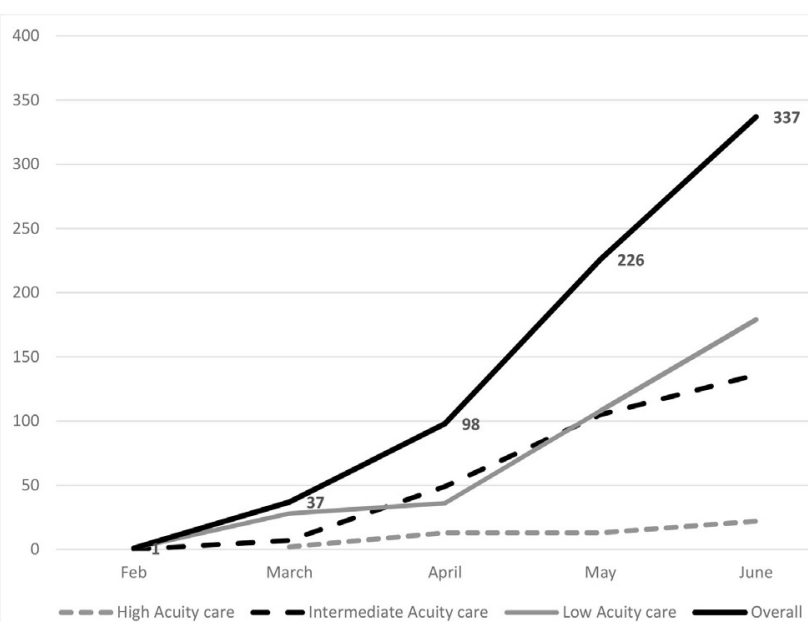

Figure 1 The trend of monthly admissions of confirmed patients with COVID-19 according to acuity level at Aga Khan University Hospital internal medicine unit ( $\mathrm{N}=699)$. 
Table 3 Effect of level of acuity cares on fatality in patients with COVID-19, HR and 95\% Cls (N=699).

\begin{tabular}{|c|c|c|c|}
\hline & \multirow[b]{2}{*}{ Univariate } & \multicolumn{2}{|l|}{ Multivariate } \\
\hline & & Model 1* & Model 2† \\
\hline & HR (95\% Cl) & HR (95\% Cl) & HR (95\% Cl) \\
\hline Low & Ref & Ref & Ref \\
\hline Intermediate & 4.6 (2.0 to 10.2$)$ & 3.4 (1.5 to 7.6$)$ & 2.7 (1.2 to 6.4$)$ \\
\hline \multicolumn{4}{|l|}{ Age group (in years) } \\
\hline $18-30$ & Ref & & \\
\hline $31-40$ & $1.2(0.2$ to 6.5$)$ & & \\
\hline $41-50$ & $0.5(0.1$ to 3.4$)$ & & \\
\hline $51-60$ & $2.4(0.5$ to 10.6$)$ & & \\
\hline Diabetes & $1.9(1.2$ to 3.1$)$ & & \\
\hline Hypertension & $0.8(0.5$ to 1.4$)$ & & \\
\hline Ischaemic heart disease & $3.0(1.9$ to 4.8$)$ & & \\
\hline Chronic lung disease & 0.8 (0.3 to 2.0$)$ & & \\
\hline Required invasive ventilation & 2.6 (1.6 to 4.2$)$ & & \\
\hline
\end{tabular}

${ }^{*}$ Adjusted for age and sex.

†Adjusted for age, sex and comorbidity including diabetes, hypertension, ischaemic heart disease and chronic lung disease.

patients fulfilled the criteria for being admitted to high acuity care but were instead admitted to intermediate care due to limited availability of high acuity beds. These were mainly those who were impending invasive ventilation (on more than $8 \mathrm{~L}$ of oxygen and required continuous NIV) or who needed limited invasive central venous pressure monitoring.

\section{Case fatality}

Overall CFR was $11.6 \%$. Comparing the case fatality between the three ALC showed that it was highest in the high acuity level patients (52\%), followed by intermediate acuity level patients (16.2\%) and $2 \%$ among low acuity care patients (table 2 ). Out of the $17 \%$ patients (141) who required high acuity care but were admitted to intermediate acuity care mentioned above, $71 \%(\mathrm{n}=100)$ survived and $29 \%(\mathrm{n}=41)$ succumbed to death by the end of the inpatient stay. In the univariate analysis, the HR (95\% CI) was 6.7 (95\% CI 2.8 to 15.9) for high acuity and $4.6(95 \%$ CI 2.0 to 10.2$)$ for intermediate acuity care compared with low acuity care. Among the covariates, age $>70$ years $(H R=5.0)$, diabetes $(H R=1.9)$, ischaemic heart disease (HR 3.0) and requiring invasive ventilation $(\mathrm{HR}=2.6)$ were associated with fatality. In the multivariate analysis after adjusting for age and sex, increased risk for death remained for intermediate acuity (HR 3.4) and high acuity care (HR 6.5) and after further adjustment of comorbidity in the final model (table 3 ). The monthly trend of CFR is shown in figure 2. For subgroup analyses of low ALC with mortality, the HR $(95 \% \mathrm{CI})$ was 0.30 (95\% CI 0.1 to 0.6 ) after adjusting for age, sex and comorbidities including diabetes, hypertension, ischaemic heart disease and chronic lung disease. There was no association of comorbidities with mortality in those admitted to low acuity care ( $p$ value 0.05 for chronic lung disease, $p$ value 0.4 for hypertension, $p$ value 0.07 for ischaemic heart disease and $p$ value 0.2 for diabetes).

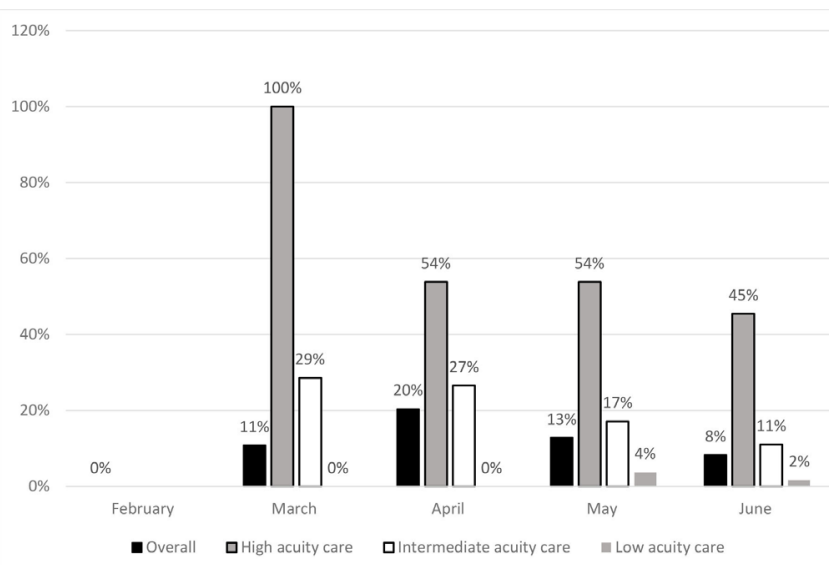

Figure 2 The trend of case fatality ratio of patients with COVID-19 according to acuity level at Aga Khan University Hospital internal medicine unit ( $\mathrm{N}=699)$. 
Table 4 Effect of level of acuity on length of stay in patients with COVID-19, beta coefficients with corresponding $95 \%$ CI $(\mathrm{N}=699)$

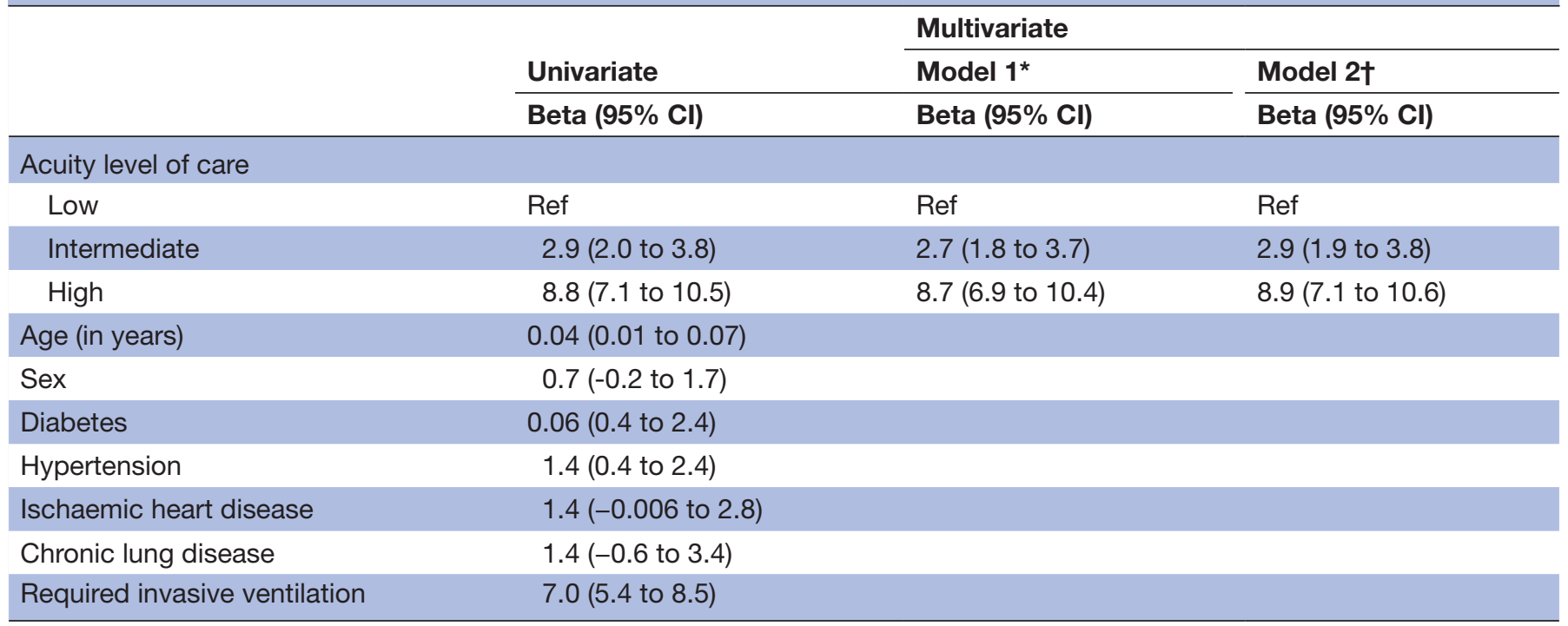

${ }^{*}$ Adjusted for age and sex.

†Adjusted for age, sex and comorbidity including diabetes, hypertension, ischaemic heart disease and chronic lung disease.

\section{Length of hospital stay}

The overall average length of stay in the hospital was 7.26 days (table 1 ). The overall median (IQR) was 6 (IQR 3-9) days. Comparing the three acuity levels, it was the longest for high-level acuity (14.2 days). In univariate analysis, the beta coefficient (95\% CI) was 8.8 (95\% CI 7.1 to 10.5$)$ for high acuity and 2.9 (95\% CI 2.0 to 3.8 ) for intermediate care. Among the covariates only requiring invasive ventilation was associated with prolonged length of stay (beta $7.0(5.4,8.5))$. In the multivariate analysis of acuity level with a length of stay, the association was increased for intermediate acuity (beta 2.7 (95\% CI 1.8 to 3.7)) and high acuity care (beta 8.7 (95\% CI 6.9 to 10.4)) after adjustment for age and sex. The association remained also after considering comorbidity (table 4). The monthly trend of an average length of stay among different acuity levels is shown in figure 3. On average, there was a 1-day reduction in overall length of stay from

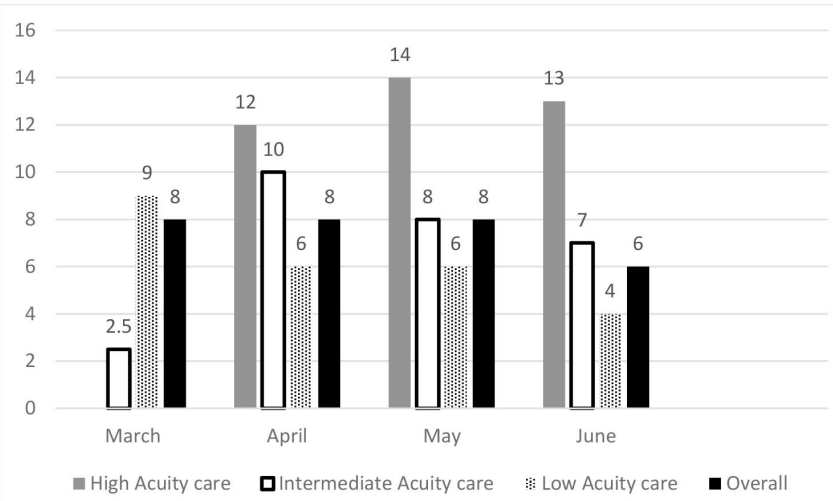

Figure 3 The average length of stay of patients with COVID-19 according to acuity level at Aga Khan University Hospital internal medicine unit $(\mathrm{N}=699)$.
February to June and a 1-day reduction in length of stay in intermediate care.

\section{DISCUSSION}

In this study, we found that the case fatality of patients with COVID-19 in our setting was highest in the high acuity care followed by intermediate care and low acuity care. The outcome was favourable (lower case fatality) of critical patients admitted to intermediate care compared with high acuity care as high acuity care beds are limited. This association was independent of age, sex and highrisk comorbid conditions including diabetes, hypertension, ischaemic heart disease and chronic lung disease. This supports the fact that the severity of the disease at the time of admission and triage into the respective care level is a strong predictor of case fatality in this patient population. A similar association was found for the length of hospital stay. The study signifies the importance of initial triaging of patients with COVID-19 into appropriate acuity levels as a predictor of outcome.

The comparable CFR in the intermediate care units implies that most patients were well managed and were able to reduce the need for high acuity care in such a resource-limited situation. ${ }^{23}$ A meta-analysis of 10 clinical studies from China on 1995 cases of COVID-19 reported a CFR of $5 \% .{ }^{24}$ Mortality in COVID-19 patients has also been reported as high as $28 \%-30 \%$ from different regions including China and the USA. ${ }^{1725}$ At the beginning of the pandemic, several European countries reported higher mortality of the initially diagnosed cases, up to $25.6 \%,{ }^{26}$ and several prognostic factors were highly associated with mortality, for example, older age and other prognostic scores such as sequential organ failure assesment, CURB$65^{26}$ or Pneumonia Severity Index, ${ }^{27}$ which could help 
improve the prognosis value of the ALC at triage as they are easy and quick to calculate. Across European countries, the CFR has been reported to be around 5\%-20\%. ${ }^{28-31}$ Case fatality varies depending on the population source. ${ }^{29}$ According to the official government portal of Pakistan capturing population-based data, the overall mortality for COVID-19 in Pakistan was 2.1\% and in Sindh (the southern province in which Karachi is located) was $1.8 \% .^{5}$ In this study, the overall case fatality from hospital-based data was $11 \%$, which is comparable and even lower than the mortality reported from hospitals of upper-middleincome countries. CFR from hospital settings in India, a neighbouring country with a similar genetic, ethnic and cultural background, was reported to be $28 \%{ }^{32}$ The reason for the variation in case fatality across the globe might be linked to underdetection of mild or asymptomatic cases or differences in medical care. ${ }^{33}$ Of note, changes in the management of COVID-19 over time with steroids and other trial drugs such as remdesivir and tocilizumab might have also impacted case fatality over time. ${ }^{3435}$ Additionally, our centre is a tertiary care centre and the first one to treat patients with COVID-19 in Pakistan, hence a significant number of patients presented with moderate-to-severe disease due to delayed presentation from within and outside Karachi. Other mechanisms including genetics, immunity and environmental factors need further exploration.

While many studies report the outcomes of COVID-19 based on the severity of the disease, comparatively fewer studies present the CFR among the different ALC of patients at admission. In a study from Italy on 174 noncritical COVID-19 patients, the CFR reported was $2.5 \%{ }^{29}$ This is identical to our rate for those who were initially admitted to low acuity care. Although high-flow oxygen therapy and NIV are not recommended in general and outside of an intensive care unit. ${ }^{21}$ NIV support techniques have been used to develop a respiratory intermediate care unit to implement non-invasive oxygenation in France. ${ }^{36}$ NIV is beneficial in the initial management of acute respiratory distress syndrome associated with SARS-CoV-2, particularly in times of ICU shortage. The same strategy was used in our intermediate care units by using NIV and hence preventing early intubation where justified. Data from an observational study on 670 consecutive patients with confirmed COVID-19, managed in an out-of-ICU setting, in nine hospitals showed an unadjusted mortality rate of $26.9 \%$; the patients in these units were managed with high-flow nasal cannula, NIV or continuous positive airway pressure. ${ }^{37}$ The CFR from our intermediate care unit was $16 \%$, thus lower than reported in the former study. The reason for this could be that our medical staff was accustomed to managing patients on NIV in a respiratory unit even before the COVID-19 pandemic, hence they might be more skilled in managing acute respiratory distress syndrome and hypoxia. ${ }^{38}$ Second, due to resource limitations in intubation of patients, we might have used NIV for longer periods or maintained a higher threshold for intubation. Third, our respiratory units for patients with COVID-19 were primarily managed by an internist and pulmonologist who were involved in consultations. As internists have experience in managing patients with multimorbidity and have a holistic approach in managing patients, this might have improved the overall outcome of these patients. For example, patients with COVID-19 are more likely to have uncontrolled diabetes and for better outcomes good glycaemic control is essential. ${ }^{39}$ A metaanalysis on 14 studies on 4659 patients reported diabetes and ischaemic heart disease as predictors of mortality in patients with COVID-19 in addition to other inflammatory and clinical parameters. ${ }^{40}$ In another meta-analysis of 6452 patients from 30 studies, diabetes mellitus doubled the risk of mortality in patients with COVID-19 and so did ischaemic heart disease. ${ }^{41} 42$ In the current study, having diabetes or ischaemic heart disease was associated with increased fatality. Hence, our findings are in alignment with the former research findings.

For patients admitted to ICUs, the case fatality had been reported to be around $40 \%-50 \%$ in the USA. ${ }^{43}{ }^{44}$ Data from six COVID-designated ICUs from Atlanta, Georgia, USA, $(\mathrm{n}=217)$ demonstrated mortality of $35.7 \%{ }^{45}$ Our CFR is $50 \%$ which is comparable to what has been reported from other regions. This relatively higher case fatality could be due to severe disease and delayed presentation to the hospital due to limited critical care facilities in the city. Second, it might also be linked to the different South Asian backgrounds of the patient population. ${ }^{46}$ In contrast, mortality rates reported from Washington, USA, $(\mathrm{n}=21)$ were as high as $67 \% .{ }^{47}$ It is useful to note here that despite being an LMIC the care provided to patients with COVID-19 was comparable to that provided in certain high-income countries. There is an urgent need for collaborative efforts of ICU practitioners, hospital administrators, governments and policy-makers to prepare for a substantial increase in critical care bed capacity, with a focus on infrastructure, supplies and staff management. ${ }^{23}$ The Sindh government is collaborating with the AKUH to provide free training and technical assistance to healthcare professionals working in the public sector in providing critical care to patients with COVID-19. ${ }^{48}$

Addressing CFR according to age indicates that it ranges from $3.5 \%$ to $20 \%$ among those aged $>60$ years in Italy and $3.6 \%-14 \%$ in the same age range in China. ${ }^{29} 49$ Our CFR shows the same trend of being higher in those aged $>$ than 60 years. However, these CFR figures might be overestimated as our data are based on clinical data and are not population based. The higher CFR in the older population might also be because they were not subjected to invasive ventilation due to poorly predicted outcomes associated with old age, frailty, comorbidities or logistic limitations due to the non-availability of ventilated beds. ${ }^{18}$ Also, the risk of having a critical disease is higher in individuals having age above 50 years or those having comorbidities, hence requiring higher ALC. This might be one reason that more elderly population was admitted in intermediate acuity level rather than low or high acuity level in this study. 
Regarding the length of hospital stays due in patients with COVID-19, a systematic review of 52 studies reported a median length of hospital stay ranging from 4 to 53 days in China and 4 to 21 days outside of China. ${ }^{19}$ For an ICU stay, it was 14 days within China and 7 days (4-11) outside China. The review further stated that the length of stay was longer for those who survived versus those who did not survive. Our overall median length of stay was 6 days with an IQR of 3-9 days, which is significantly lower than what is reported from China, although the median ICU stay was similar, 12 (IQR 8-19), and similar to ICU stays elsewhere. A potential reason for a considerably lower median stay in non-critical patients might be that the pandemic lagged behind in countries outside of China, which might have provided ample opportunity for these countries to use trial drugs including steroids, tocilizumab and remdesivir which potentially contributed to improved outcomes. ${ }^{50-52}$

The strength of our study is that it is the first of its kind to report the association between ALC of patients with COVID-19 and CFR from a hospital in an LMIC. This centre is the pioneer hospital in a city of 17 million people that started treating critical patients with COVID-19, hence the results do have implications as a guidance for other hospitals that treat patients with COVID-19. The study was able to adjust not only for the bias of confounding by sex and age but also for important comorbidities. Nonetheless, there are several limitations to the study. This is a singlecentre study; hence, the results are not generalisable to the entire population. Also, the severity of patients based on radiological and laboratory parameters has not been reported in this study as we relied on data regarding acuity level. Also, only a limited number of common comorbid conditions were investigated and compared across acuity levels and mortality; expanded clinical datasets would be beneficial to investigate for further research. We also did not report data on different drugs that were used in the treatment of COVID-19.

\section{CONCLUSION}

High and intermediate acuity levels are associated with higher CFRs and prolonged length of hospital stay in patients with COVID-19 compared with patients admitted to low acuity levels. In resource-limited settings where the provision of high acuity care is limited, the intermediate care acuity could serve as a useful strategy to treat relatively less critical patients with COVID-19. It is important to accurately triage patients with COVID-19 based on the level of care as improvements in clinical outcomes and overall survival depends on it. In LMIC such as Pakistan, government and private sector hospitals can aim to develop more intermediate care units in addition to intensive care units for useful and cost-effective care of patients.

Acknowledgements The authors thank the dedicated support of Ambreen Amirali and Saadia Farooqui for data collection and management.
Contributors AA and ZM: designed study protocol, performed the data quality control and the statistical analysis and oversaw the daily data log. ZM: applied for ethical approval. JM: contributed to overseeing the statistical analysis of the study. All authors: drafted the manuscript and participated in revising the manuscript and approved the final version.

Funding The authors have not declared a specific grant for this research from any funding agency in the public, commercial or not-for-profit sectors.

Competing interests None declared.

Patient and public involvement Patients and/or the public were not involved in the design, or conduct, or reporting, or dissemination plans of this research.

Patient consent for publication Not required.

Ethics approval All study procedures and materials were reviewed and approved by the Ethics Review Committee, Aga Khan University (ERC number 2020-5175-11220).

Provenance and peer review Not commissioned; externally peer reviewed.

Data availability statement Data are available upon reasonable request to the corresponding author.

Open access This is an open access article distributed in accordance with the Creative Commons Attribution Non Commercial (CC BY-NC 4.0) license, which permits others to distribute, remix, adapt, build upon this work non-commercially, and license their derivative works on different terms, provided the original work is properly cited, appropriate credit is given, any changes made indicated, and the use is non-commercial. See: http://creativecommons.org/licenses/by-nc/4.0/.

ORCID iD

Aysha Almas http://orcid.org/0000-0001-7146-7183

\section{REFERENCES}

1 Coronavirus disease (COVID-19). Available: https://www.who.int/ docs/default-source/coronaviruse/situation-reports/20200602-covid19-sitrep-134.pdf?sfvrsn=cc95e5d5 2WHO

2 Adhikari SP, Meng S, Wu Y-J, et al. Epidemiology, causes, clinical manifestation and diagnosis, prevention and control of coronavirus disease (COVID-19) during the early outbreak period: a scoping review. Infect Dis Poverty 2020;9:1-12.

3 Singhal T. A review of coronavirus disease-2019 (COVID-19). The Indian Journal of Pediatrics 2020;87:281-6.

4 World Health Organization. Clinical management of severe acute respiratory infection (SARI) when COVID-19 disease is suspected: interim guidance. World Health Organization, 2020.

5 SindhCOVID-19 statistics, 2020. Available: http://covid.gov.pk/stats/ pakistan

6 Brennan CW, Daly BJ. Patient acuity: a concept analysis. J Adv Nurs 2009:65:1114-26.

7 Hughes R. Patient safety and quality: an evidence-based handbook for nurses. Vol 3. Rockville, MD: Agency for Healthcare Research and Quality, 2008.

8 West E, Barron DN, Harrison D, et al. Nurse staffing, medical staffing and mortality in intensive care: an observational study. Int J Nurs Stud 2014:51:781-94.

9 Liu X, Zhou H, Zhou Y, et al. Risk factors associated with disease severity and length of hospital stay in COVID-19 patients. J Infect 2020:30216-4.

10 Ayebare RR, Flick R, Okware S, et al. Adoption of COVID-19 triage strategies for low-income settings. Lancet Respir Med 2020;8:e22.

11 Truog RD, Mitchell C, Daley GQ. The Toughest triage allocating ventilators in a pandemic. $N$ Engl J Med Overseas Ed 2020;382:1973-5.

12 Worster A, Fernandes CM, Eva K, et al. Predictive validity comparison of two five-level triage acuity scales. Eur J Emerg Med 2007;14:188-92.

13 Garland A, Ashton-Cleary D, Sinclair R. Inpatient illness severity surveys provide essential data for planning capacity and managing patient flow in the acute hospital setting. J Intensive Care Soc 2016;17:196-201.

14 Fernandes CMB, Tanabe P, Gilboy N, et al. Five-level triage: a report from the ACEP/ENA five-level triage task force. J Emerg Nurs 2005;31:39-50.

15 Wuerz RC, Milne LW, Eitel DR, et al. Reliability and validity of a new five-level triage instrument. Acad Emerg Med 2000;7:236-42.

16 Considerations for alternate care sites. Available: https://www.cdc. gov/coronavirus/2019-ncov/hcp/alternative-care-sites.html 
17 Zhou F, Yu T, Du R, et al. Clinical course and risk factors for mortality of adult inpatients with COVID-19 in Wuhan, China: a retrospective cohort study. Lancet 2020;395:1054-62.

18 Vincent J-L, Taccone FS. Understanding pathways to death in patients with COVID-19. Lancet Respir Med 2020;8:430-2.

19 Rees EM, Nightingale ES, Jafari Y, et al. COVID-19 length of hospital stay: a systematic review and data synthesis. BMC Med 2020;18:270.

20 COVID Tele-ICU, 2020. Available: https://www.aku.edu/Pages/covidicu.aspx

21 Swiss Society Of Intensive Care Medicine. Recommendations for the admission of patients with COVID-19 to intensive care and intermediate care units (ICUs and IMCUs). Swiss Med Wkly 2020;150:w20227.

22 Ghani AC, Donnelly CA, Cox DR, et al. Methods for estimating the case fatality ratio for a novel, emerging infectious disease. Am J Epidemiol 2005;162:479-86.

23 Phua J, Weng L, Ling L, et al. Intensive care management of coronavirus disease 2019 (COVID-19): challenges and recommendations. Lancet Respir Med 2020;8:506-17.

24 Li L-Q, Huang T, Wang Y-Q, et al. COVID-19 patients' clinical characteristics, discharge rate, and fatality rate of meta-analysis. $J$ Med Virol 2020;92:577-83.

25 Price-Haywood EG, Burton J, Fort D, et al. Hospitalization and mortality among black patients and white patients with Covid-19. N Engl J Med 2020;382:2534-43.

26 Rivera-Izquierdo M, del Carmen Valero-Ubierna M, R-delAmo $\mathrm{JL}$, et al. Sociodemographic, clinical and laboratory factors on admission associated with COVID-19 mortality in hospitalized patients: a retrospective observational study. PLoS One 2020;15:e0235107.

27 Satici C, Demirkol MA, Sargin Altunok E, et al. Performance of pneumonia severity index and CURB-65 in predicting 30-day mortality in patients with COVID-19. Int J Infect Dis 2020;98: :84-9.

28 Karadag E. Increase in COVID-19 cases and case-fatality and caserecovery rates in Europe: a cross-temporal meta-analysis. J Med Virol 2020;92:1511-7.

29 Onder G, Rezza G, Brusaferro S. Case-fatality rate and characteristics of patients dying in relation to COVID-19 in Italy. JAMA 2020;323:1775-6.

30 Pellaud C, Grandmaison G, Pham Huu Thien HP, et al. Characteristics, comorbidities, 30-day outcome and in-hospital mortality of patients hospitalised with COVID-19 in a Swiss area - a retrospective cohort study. Swiss Med Wkly 2020;150:w20314.

31 Giacomelli A, Ridolfo AL, Milazzo L, et al. 30-day mortality in patients hospitalized with COVID-19 during the first wave of the Italian epidemic: a prospective cohort study. Pharmacol Res 2020;158:104931.

32 Aggarwal A, Shrivastava A, Kumar A, et al. Clinical and epidemiological features of SARS-CoV-2 patients in SARI ward of a tertiary care centre in New Delhi. J Assoc Physicians India 2020;68:19-26.

33 Battegay M, Kuehl R, Tschudin-Sutter S, et al. 2019-nove Coronavirus (2019-nCoV): estimating the case fatality rate - a word of caution. Swiss Med Wkly 2020;150:w20203.

34 Zain Mushtaq M, Bin Zafar Mahmood S, Jamil B, et al. Outcome of COVID-19 patients with use of tocilizumab: a single center experience. Int Immunopharmacol 2020;88:106926.
35 Horby P, Lim WS, Emberson JR. Dexamethasone in hospitalized patients with Covid-19 2020.

36 Guenancia TN, Rosa A, Damoisel C, et al. Implementation of a non-invasive oxygenation support strategy during the COVID-19 pandemic in an ephemeral respiratory intermediate care unit. Anaesth Crit Care Pain Med 2020;39:459-60.

37 Franco $\mathrm{C}$, Facciolongo N, Tonelli R, et al. Feasibility and clinical impact of out-of-ICU noninvasive respiratory support in patients with COVID-19-related pneumonia. Eur Respir J 2020;56:2002130. doi:10.1183/13993003.02130-2020

38 Bedford J, Enria D, Giesecke J, et al. COVID-19: towards controlling of a pandemic. Lancet 2020;395:1015-8.

39 Apicella M, Campopiano MC, Mantuano M, et al. COVID-19 in people with diabetes: understanding the reasons for worse outcomes. Lancet Diabetes Endocrinol 2020;8:782-92.

40 Tian W, Jiang W, Yao J, et al. Predictors of mortality in hospitalized COVID-19 patients: a systematic review and meta-analysis. J Med Virol 2020;92:1875-83.

41 Huang I, Lim MA, Pranata R. Diabetes mellitus is associated with increased mortality and severity of disease in COVID-19 pneumonia - A systematic review, meta-analysis, and meta-regression. Diabetes Metab Syndr 2020;14:395-403.

42 Inciardi RM, Adamo M, Lupi L, et al. Characteristics and outcomes of patients hospitalized for COVID-19 and cardiac disease in northern Italy. Eur Heart J 2020;41:1821-9.

43 Wiersinga WJ, Rhodes A, Cheng AC, et al. Pathophysiology, transmission, diagnosis, and treatment of coronavirus disease 2019 (COVID-19): a review. JAMA 2020;324:782

44 Bhatraju PK, Ghassemieh BJ, Nichols M, et al. Covid-19 in Critically III Patients in the Seattle Region - Case Series. N Engl J Med 2020;382:2012-22.

45 Auld SC, Caridi-Scheible M, Blum JM, et al. ICU and ventilator mortality among critically ill adults with coronavirus disease 2019 Crit Care Med 2020;48:e799-804.

46 Pan D, Sze S, Minhas JS, et al. The impact of ethnicity on clinica outcomes in COVID-19: a systematic review. EClinicalMedicine 2020;23:100404.

47 Arentz M, Yim E, Klaff L, et al. Characteristics and outcomes of 21 critically ill patients with COVID-19 in Washington state. JAMA 2020;323:1612-4.

48 Interim infection prevention and control recommendations for healthcare personnel during the coronavirus disease 2019 (COVID-19) pandemic. Available: https://www.cdc.gov/coronavirus/ 2019-ncov/hcp/infection-control-recommendations.html [Accessed 3 May 2020].

49 Surveillances $\mathrm{V}$. The epidemiological characteristics of an outbreak of 2019 novel coronavirus diseases (COVID-19) - China, 2020. China CDC Weekly 2020;2:113-22.

50 Anderson M, Bach P, Baldwin MR. Hospital length of stay for severe COVID-19: implications for Remdesivir's value. medRxiv 2020.

51 Eimer J, Vesterbacka J, Svensson A-K, et al. Tocilizumab shortens time on mechanical ventilation and length of hospital stay in patients with severe COVID-19: a retrospective cohort study. J Intern Med 2021;289:434-6.

52 Isidori AM, Arnaldi G, Boscaro M, et al. COVID-19 infection and glucocorticoids: update from the Italian Society of endocrinology expert opinion on steroid replacement in adrenal insufficiency. $J$ Endocrinol Invest 2020;43:1141-7. 